(C) The Author(s), 2020. Published by Cambridge University Press on behalf of The Nutrition Society. This is an Open Access article, distributed under the terms of the Creative Commons Attribution licence (http://creativecommons.org/licenses/by/4.0/), which permits unrestricted re-use, distribution, and reproduction in any medium, provided the original work is properly cited.

\title{
Processing in the food chain: do cereals have to be processed to add value to the human diet?
}

\author{
Frank Thielecke ${ }^{1,2 *}$ (1) , Jean-Michel Lecerf ${ }^{3}$ and Anne P. Nugent ${ }^{4,5}$ (1) \\ ${ }^{1}$ Swiss Distance University of Applied Sciences, Regensdorf-Zurich, Switzerland \\ ${ }^{2}$ T2Bene LTD, Bettenstrasse 60a, 4123 Allschwil, Switzerland \\ ${ }^{3}$ Nutrition Department, Institut Pasteur de Lille, 59019 Lille Cedex, France \\ ${ }^{4}$ Institute for Global Food Security, School of Biological Sciences, Queen's University Belfast, 02.0014 Northern Ireland \\ Technology Centre, Cloreen Park, Belfast BT9 5HN, UK \\ ${ }^{5}$ UCD Institute of Food and Health, School of Agriculture and Food Science, University College Dublin, Belfield, Dublin 4, \\ Republic of Ireland
}

\begin{abstract}
Cereals and cereal products have a long history of use by humans. Recently, there have been some discussions regarding level of processing as a descriptor to define food products, including cereal-based foods. This has led to a somewhat emotional debate on food processing. Given the widespread inclusion of cereals in the diet, this review highlights the history of cereal processing as well as their consumption by humans. It provides an evidence-based discussion on their production, contribution to human nutrition, benefits and disadvantages. The present review illustrates the impact of processing on nutrients, as well as non-nutrients specifically in bread and ready-to-eat breakfast cereals (RTEC), two cereal-based foods which are widely consumed and integral parts of food-based dietary guidelines globally. As a category, most cereals must be processed in some way to enable consumption by humans as we are not equipped to survive exclusively on raw grains. Even thousands of years ago, the processing of cereals was a common practice by humans, turning raw grains into palatable, safe and nutritious foods. Modern processes for cereal-based products are efficient in providing safe and good-quality products to satisfy population needs, as well as helping to meet consumer expectations by providing a range of foods that allows for a varied and balanced diet. Today, RTEC and bread make significant contributions to dietary energy and nutrient requirements and underpin food-based dietary guidance globally. They have been positively linked with intake of dietary fibre, vitamins and minerals, especially when consumed as whole grain.
\end{abstract}

Key words: Cereal-based foods: Bread: Ready-to-eat breakfast cereals: Processing: Nutrients

(Received 22 November 2019; revised 22 July 2020; accepted 18 August 2020; accepted manuscript published online 28 August 2020)

\section{Introduction}

Over 50000 plants are edible, but very few of them make any significant contribution to the human food supply. Cereals such as maize, rice and wheat together make up about $60 \%$ of the world's energy intake ${ }^{(1)}$. Currently, the average annual global production of wheat is about 734 million tonnes $^{(2)}$. Only maize has, at 1.14 million tonnes, a higher global production.

Cereals and cereal products have a long history of use by humans. Cereals make significant contributions to dietary energy and nutrient requirements and are sometimes referred to as a 'dietary staple', along with milk, fruit and vegetables. Cereals underpin food-based dietary guidance globally. Scientific discussion regarding cereals has typically related to quantity and quality within the human diet, for example, low- or highcarbohydrate diets, whole or refined cereal. However, there has been some recent debate regarding level of processing as a descriptor to define food products, including cereal-based ones. The aim of this paper is to shed light on the fundamental processes for cereal-based foods as currently consumed and any implications for nutritional value in the context of a healthy diet. Using ready-to-eat breakfast cereals (RTEC) and breads as examples of globally consumed cereal-based food products, the review will compare the processes used in their generation and outline their importance in making nutrients available and helping to achieve dietary balance.

\section{History of cereal processing and consumption by humans}

The inclusion of cereals in the diet was an important step in human evolution as it is an example of how humans were able to increase the supply of digestible carbohydrates by creating solutions to the technical complexity and culinary manipulation needed to change raw cereals into palatable and nutritious foods or staples. Most scientists believed that the domestication of grains began about some 10000 years ago, but more recent findings may put this time point substantially earlier. An ancient site

Abbreviations: EFSA, European Food Safety Authority; EU, European Union; RTEC, ready-to-eat breakfast cereal.

* Corresponding author: Frank Thielecke, email frank.thielecke@ffhs.ch 
in Israel contained a collection of cereals, which were dated to about 23000 years ago ${ }^{(3)}$, suggesting that cereal storage preceded domestication by about 10000 years. The first processing of cereals might date back even further as evidence suggests that some early Homo sapiens were eating starchy, cereal-based snacks as early as 105000 years ago ${ }^{(4)}$. For example, grass seed residue, mainly sorghum, has been found on ancient African stone tools, which in turn suggests an early application of processing to make the seeds consumable. More recently, about 30000 years ago, plant food processing including the production of flour was a common practice across Europe ${ }^{(5)}$. As early as about 7000 BC people in Greece were cultivating wheat, barley and oats ${ }^{(6)}$. Anecdotal evidence suggests that the troops of Hannibal, the Carthaginian general, ate porridge before and during their famous crossing of the Alps (218 BC).

\section{Rationale for food processing}

Simplistically, food processing can be described as any deliberate change in a food that occurs before it is available to people in a form and time that it is required ${ }^{(7,8)}$. Food processing is therefore critical for food consumption as it typically turns inedible raw materials into more useful, shelf-stable and palatable foods or drinks fit for human consumption ${ }^{(9)}$. This basic need as well as safety was one of the key drivers of the creation of food processing. Food processing has since evolved to satisfy more modernday purposes which can be expanded as follows: (1) to make food edible; (2) to ensure safety of food; (3) to increase palatability (better tasting and greater access to nutrients) ${ }^{(10)}$; and (4) to produce convenient foods ${ }^{(10)}$.

Positive outcomes of food processing therefore include an increase in the useful life of foods, destruction of food-borne microbes and toxins, optimised nutrient availability, improved characteristics of food quality such as sensory characteristics and functional properties, increased convenience and reduced losses and waste ${ }^{(7,11,12)}$. Ultimately this provides greater choice and variety of safe products for the consumer. There may, however, be less desirable outcomes following processing, one example being an increased availability of starch which can facilitate rapid digestion and blood glucose elevation, especially if grain products are consumed as refined-grain products ${ }^{(13)}$. To prevent such downsides, an opportunity exists to optimise grain processing to improve nutritional value and make whole grains easier to use in food manufacturing.

Currently, there are a myriad of definitions about how to describe or classify processed foods, which have been described in detail elsewhere ${ }^{(14)}$. These include descriptions by scientific authorities, for example, the European Food Safety Authority (EFSA), where processed food is simply defined within the definition of 'food" ${ }^{\text {(15) }}$ to more complex descriptions by non-profit organisations (for example, International Food Information Council $^{(9)}$ ) or groups of scientists (for example, NOVA) where more detailed but differing categorisations have been developed $^{(16,17)}$. This may have contributed to the current standing where despite the long tradition of humans processing food, particularly cereals, today there is some confusion or uncertainty around processed foods and about what processing of food

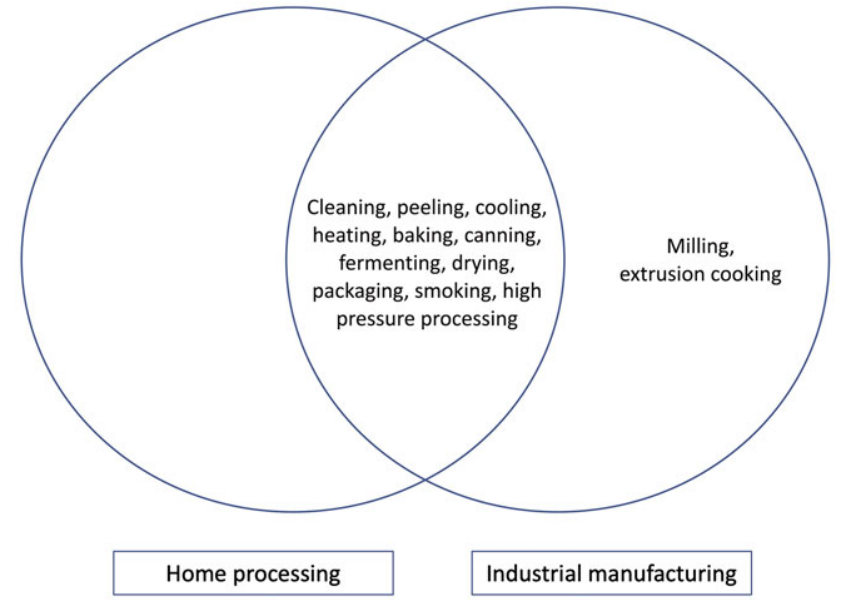

Fig. 1. Most of the common food processing techniques are similar in home and industrial manufacturing (modified from the European Food Safety Authority ${ }^{(79)}$ ).

means among a number of scientists as well as some consumers. In fact, many food processing techniques are common to both homes and food manufacturers (Fig. 1).

\section{Main aspects of cereal processing}

Processing of cereals is required before human consumption, as Rubel $^{(18)}$ explained:

Humans are not equipped to live on raw grain as we have neither the teeth or the stomachs for it. We must transform grains into food through cooking, with basic methods of sprouting, fermenting, roasting, boiling and baking. Grinding and baking into breads radically increases a grain's glycaemic index releasing otherwise unavailable carbohydrates.

In principle, cereal processing is essentially a physical process whereby the kernel is cleaned, adjusted to an appropriate moisture content and then mechanically reduced to the desired particle size to produce a flour and by-products (for example, bran). Where appropriate, flour production also involves fractionation - not only to separate bran, germ and endosperm from each other but also to assure the correct particle size of the milled endosperm. There are a number of processing steps for cereals between harvest and consumption. While each type of cereal requires specific treatment steps, the FAO suggest three distinct areas such as (1) preparation of the cereal for storage; (2) primary cereal processing to remove inedible fractions; and (3) secondary processing to transform cereals into 'consumer-facing' products (see Fig. 2) ${ }^{(19)}$. Generally speaking, cereal products undergo all three processing steps before being consumed by humans.

At a European level, the European Union (EU) Commission ${ }^{(20)}$ mentions processing but only in the context of establishing maximal levels of certain contaminants within a foodstuff whereby:

"First-stage processing" shall mean any physical or thermal treatment, other than drying, of or on the grain. Cleaning, sorting and drying procedures are not considered to be "first-stage processing" insofar as no physical action is exerted on the grain kernel itself and the whole grain remains intact after cleaning and sorting. In integrated production and processing systems, the maximum level applies to the unprocessed cereals in case they are intended for first-stage processing. 

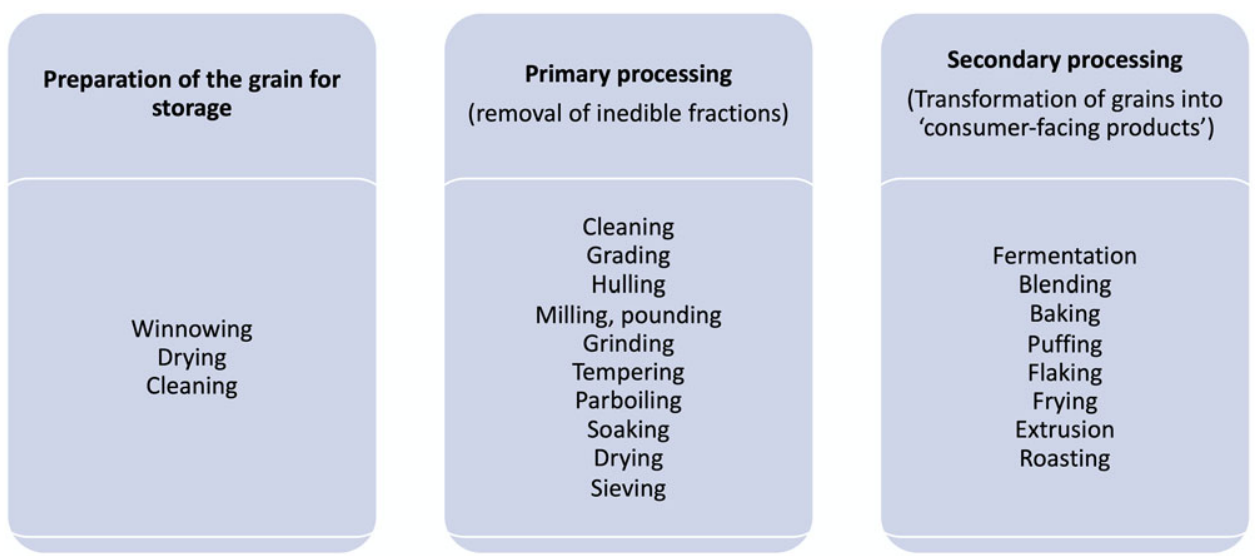

Fig. 2. Principal processing steps of grains, modified from the $F A O^{(19)}$.

Given this EU focus is directed at contamination of food rather than processing per se, for the scope of the present review we adhere to the more targeted FAO definition and discuss the primary and secondary processing steps of two key cereal products: flaked RTEC and bread. We acknowledge that there are many types of breakfast cereals with a varying range of processing steps. We have chosen flaked RTEC as an example of grain products since their production process demonstrates a variety of processing steps. Further, there is a significant history of humans eating both foods. Bread making is one of the oldest but also the most common processing technique for cereals, with reports of bread consumption by ancient Greeks, Egyptians and people belonging to ancient Rome and Babylon ${ }^{(21)}$. While breakfast cereals in the form of porridge have a similar long history to bread, there is a much shorter history of use for RTEC, but their presence on the market is nonetheless significant, with the first RTEC appearing over 100 years ago in the late nineteenth century ${ }^{(22)}$. The per capita consumption of RTEC in 2020 stands at $3.7 \mathrm{~kg}$ in France, $6.1 \mathrm{~kg}$ in the UK, $8.8 \mathrm{~kg}$ in Ireland, $6.5 \mathrm{~kg}$ in the USA and $5.2 \mathrm{~kg}$ in Canada ${ }^{(23)}$.

\section{Ready-to-eat breakfast cereals and breads: processing steps involved}

In general, all cereal-based foods have common primary processing steps. They involve cleaning, sorting and removal of the inedible fractions from the cereals followed by milling. In contrast, secondary processing of cereals (or 'adding value') is the utilisation of the primary products (whole grains, flakes or flour) to enhance shelf-stability of cereal foods and make them sensorially more attractive for consumers. Any processing should be used as an opportunity to improve recipe formulations such as replacing refined grain with whole grain and reducing composition of added sugar, fat and salt, thereby helping products attain a healthier profile. The fundamental technology applied to both RTEC and bread is heat treatment in various forms to both RTEC and bread. Details of the main steps relevant to breads and flaked RTEC and their purpose are summarised below. Processing steps vary according to desired criteria of the endproduct. Describing the entire spectrum of processes would be beyond the scope of the present review; hence we confine ourselves to the principal processes involved in flaked RTEC and bread.

Flaked breakfast cereals. Depending on the desired properties of the endproduct breakfast cereal, the processes involved may vary considerably. Examples of processes include mixing, cooking, extruding, drying, cooling, tempering, flaking, drying/toasting and packaging. The US Environmental Protection Agency has schematically outlined the basic processing steps for flaked cereals and extruded flaked cereals as adapted here (Fig. 3).

The initial preparation of the cereals for this process depends on the starter grain. For example, maize requires dry milling to remove the germ and the bran from the kernel, leaving the endosperm. Wheat kernels are first steamed and then gently passed through a pair of rolls to break open the kernels without producing flour at this point. Rice, on the other hand, requires only milling to form the polished head rice that is the normal starting material. The physical processes of flaking, puffing, shredding, extruding and expanding are sometimes described as 'texturising'.

An important texturising step for flaked cereals is extrusion, a process which increasingly replaces the more traditional cooking and delumping steps. However, it is often overlooked that extrusion is widely used in the production of other foods, such as pasta, hence here we discuss extrusion for RTEC and pasta together. Since the 1930s, pasta and breakfast cereals have been produced using extrusion processes ${ }^{(24)}$. In simple terms, for RTEC, extrusion and expansion alter the surface:volume ratios to allow for shaping and production of crisp, crunchy products, which addresses consumer demands. For pasta, extrusion enables a variety of different shapes that consumers can purchase, for example, spaghetti, campanelle, chifferi, farfalle, conchiglie and many others. The effectiveness of the extrusion step for either food form is dependent upon factors such as nutritional composition (for example, protein, fibre, carbohydrate content), structure (for example, particle size, proportion of bran) and moisture content achieved in the upstream processes. In general, cooking, drying and toasting, which are applied in traditional as well as extrusion manufacturing, introduce thermal energy to the products, with texturising operations applied during extrusion exerting additional mechanical energy on the dough ${ }^{(25)}$. 


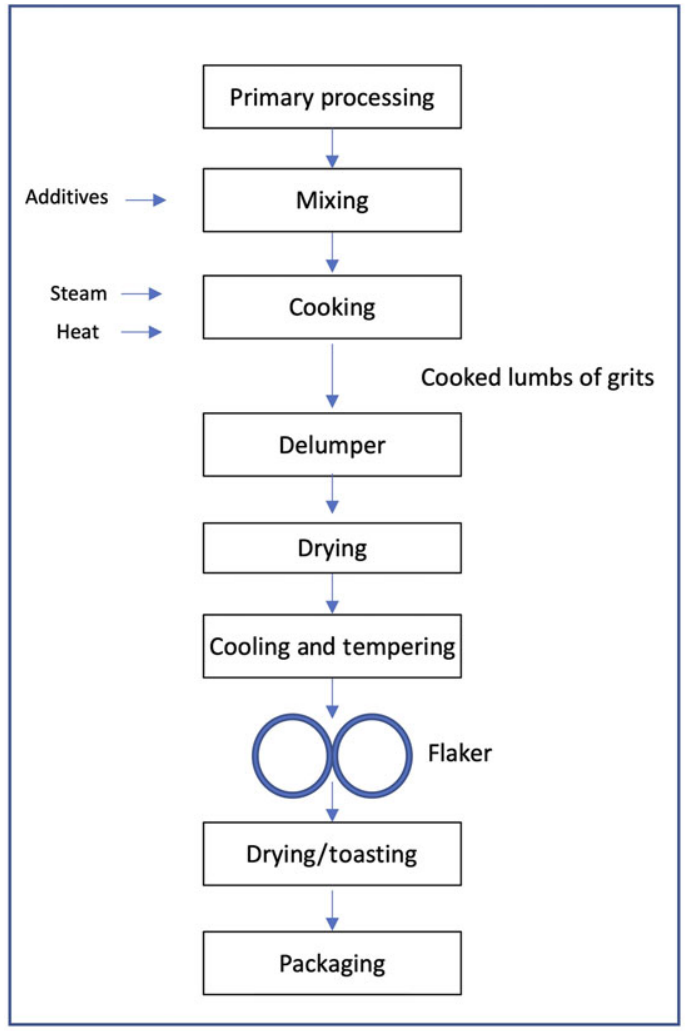

Traditional process for cereal flakes

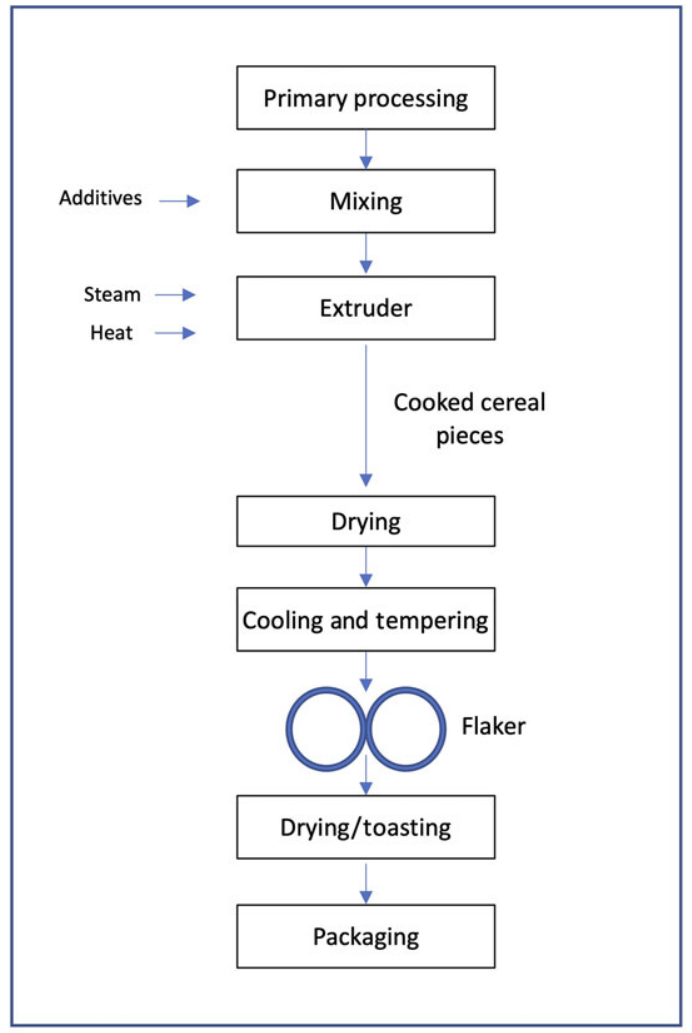

Diagram for extruded flake production

Fig. 3. Traditional processes for flaked cereals (left panel) and extruded flake production (right panel), modified from the Ministry of Health of Brazil(116).

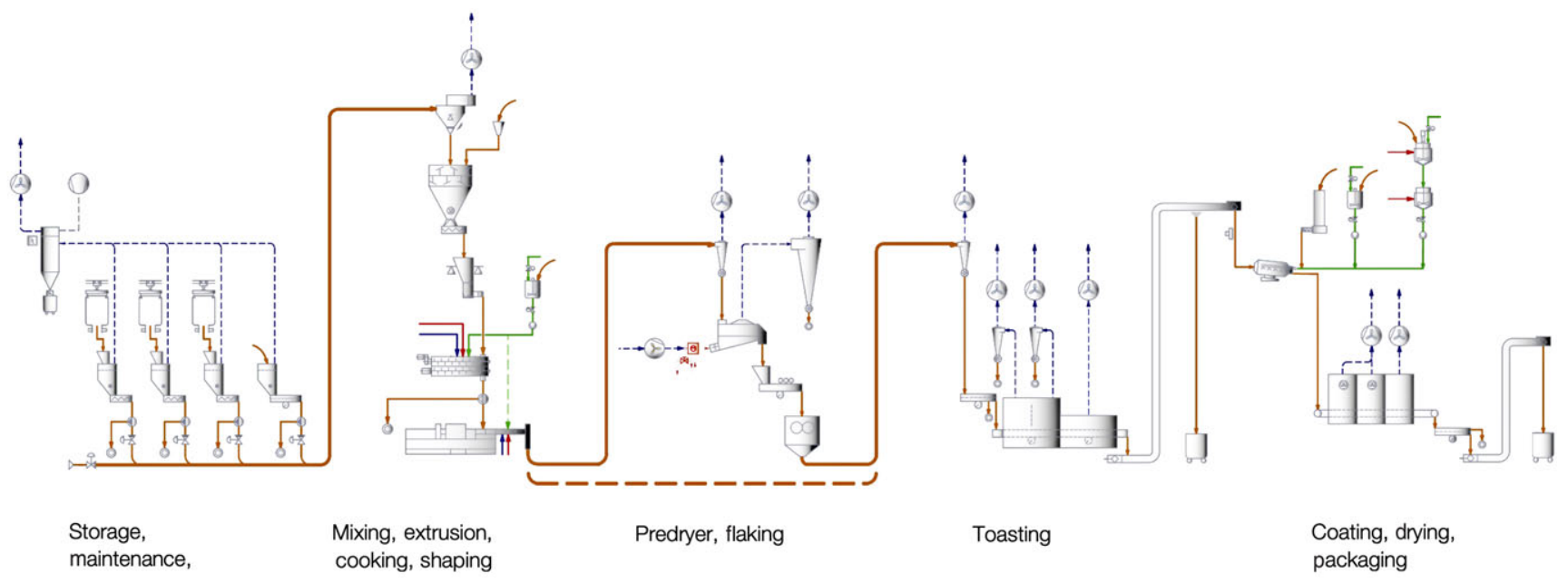

Fig. 4. Modern breakfast cereal manufacturing (provided courtesy of Bühler AG, Switzerland).

Nowadays, those processes are often combined in one manufacturing (extrusion) line. Extrusion cooking of RTEC provides several advantages over traditional methods. Extrusion cooking allows for faster processing times, lower processing costs, and greater flexibility leading to greater variability of endproducts ${ }^{(26)}$. From a consumer perspective, extrusion cooking creates cereals that are easy to chew and come in different shapes. During the manufacture of RTEC, extrusion cooking uses temperature, pressure and shear in varying intensities, depending on the types of ingredients and the desired characteristics of the endproducts ${ }^{(27)}$. A modern manufactory line for extruded RTEC is shown in Fig. 4. These manufacturing lines allow very precise control of process parameters while ensuring high efficiency and variability in output, i.e. selection of RTEC to meet consumers' demands. The effects of extrusion on nutritional quality are complex. Like many other processes that involve heating food at a high temperature before consumption, such as baking or frying, the nutritional quality may change during extrusion. As a principle, 
just like with pasta, the extrusion process for RTEC starts with mixing cereal grains into a dough. High temperature extrusion for a short time may minimise losses in vitamins and amino acids and improve protein quality and digestibility ${ }^{(28)}$. On the other hand, fragmentation of proteins and starches may occur ${ }^{(29)}$, the latter being implicated in an increased glycaemic response, possibly resulting in blood glucose elevation. In simplified terms, nutritional quality has been reported to improve with short duration, high moisture and low temperature, whereas negative effects on nutritional quality have been reported with high temperature $\left(>200^{\circ} \mathrm{C}\right)$ and low moisture $(<15 \%)^{(30)}$. More recently, it has been shown that introducing amaranth or buckwheat, as well as whole grain, significantly reduces the rate of carbohydrate hydrolysation in the human digestive tract, which positively affects the glycaemic index of the extruded RTEC or pasta ${ }^{(31,32)}$. The glycaemic index is considered a marker for nutritional quality of carbohydrate-rich foods.

For RTEC, extrusion is often followed by coating, a process where for example heat-liable vitamins and/or sugar are added. Adding sugar during processing is fundamental for many different functions, not limited to caramelisation, and is responsible for inter alia colour and flavour aspects. Whilst such added sugar has a variety of purposes during processing, its excessive consumption has been implicated with dental caries and with increased risks for various chronic diseases including obesity, diabetes and CVD. The strongest body of evidence relates dental caries and frequency of intake of sugar-containing foods ${ }^{(33)}$. However, to date, there is no firm conclusion that added sugar is related to the above metabolic diseases ${ }^{(34)}$, with the strongest available evidence for sugar-containing beverages rather than sugar per $s e^{(34)}$. Nonetheless, it would be prudent to consume added sugars in moderation.

Bread. Globally, the techniques for making bread can vary but essentially use four essential ingredients: flour, water, yeast and salt ${ }^{(35)}$. Nonetheless, bread making is also a complex process that involves many physiochemical and structural changes to yield the final aerated baked product ${ }^{(36)}$. Fig. 5 provides a general outline of key steps involved.

Within the bread-making processes differences can also exist, particularly with respect to extraction rates during milling and fermentation processes used. A higher extraction rate allows for a higher percentage of outer grain layers to be retained with $100 \%$ extraction rates yielding whole-grain flours. In contrast, white flours typically have lower extraction rates, as low as $70-72 \%{ }^{(36,37)}$.

Differences in fermentation can also arise depending on bread type (for example, sourdough) or whether mainstream mixing and fermentation processes are used. Sourdoughs (a commonly consumed bread type globally) are created when flour and water are mixed and then fermented with yeast and with homo- and hetero-fermentative lactic acid bacteria, increasing the lactic and acetic acid concentrations and resulting in a sour-taste product. The final taste can also vary depending on the cereal used (wheat, rye, oat, barley or maize), the microbial population present and ratio of bacteria:yeast used ${ }^{(38,39)}$. Some other popular types of bread globally include baguettes,

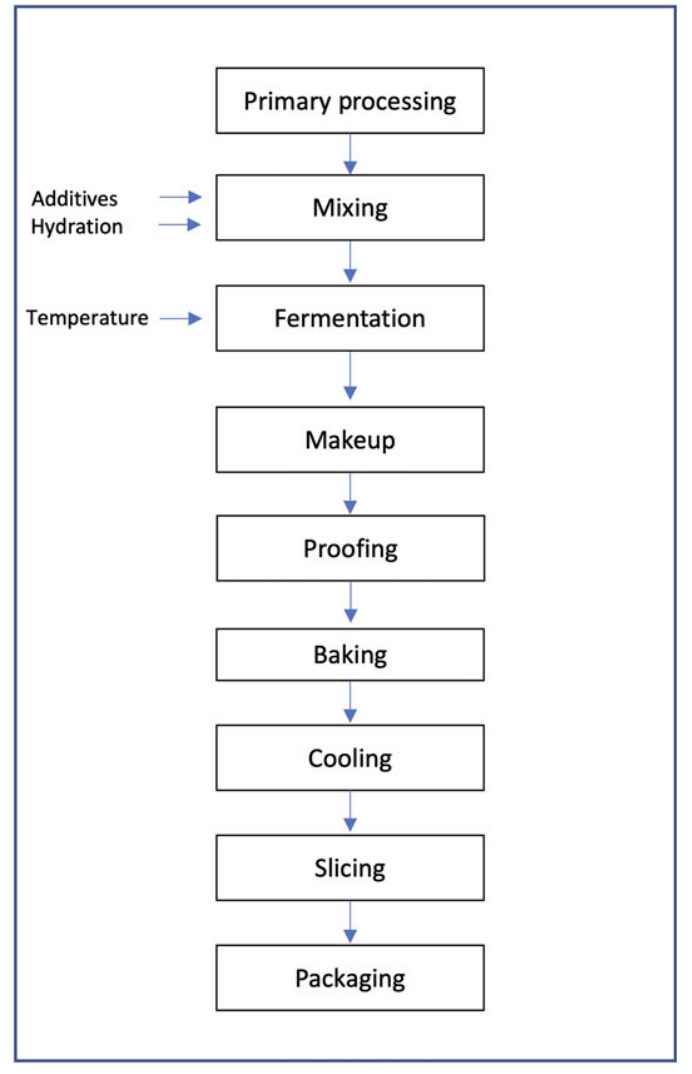

Fig. 5. Traditional process for bread making (sourced from BAKERpedia(126)).

ciabattas, various flat breads, rye or maize breads ${ }^{(38)}$. However, in some countries, such breads may be viewed as artisan, where the term 'bread' is typically associated with white or brown pre-packaged or pre-sliced loafs or pans. Currently, bakeries and food business operators can use two main methods to make such prepacked bread which differ only with respect to their mixing and fermentation stages; the bulk fermentation process (BFP) and the Chorleywood bread process $(\mathrm{CBP})^{(40)}$. The BFP is the more traditional method where ingredients are mixed and the dough left to ferment for up to $3 \mathrm{~h}$. During this fermentation phase, the mixture changes to form an elastic dough. In contrast, the CBP uses mechanical energy in the form of high-speed mixing as a type of kneading to develop the dough for proving and baking. A little fat or emulsifier and a treatment agent (for example, ascorbic acid) are typically added as an improver to aid this process. Soya flour may also be added to soften the bread, provide food for the yeast, hold water, keep the bread moist and help improve the natural colour of the bread. First developed in the 1960s in Chorleywood, UK, this CBP method was highly successful as it enabled a much faster production of bread to satisfy consumer need ${ }^{(40)}$. Hence, the processes of making bread are complex and varied but ultimately result in a processed cereal product which is commonly consumed.

Comparison of processing of bread and ready-to-eat breakfast cereals. There are many steps common to the processing of both RTEC and bread. Using 'wheat' as an example, it is 
Table 1. Overview of the generic processing steps for wheat-based cereals, highlighting those steps used in the manufacture of ready-to-eat breakfast cereal (RTEC) flakes and bread*

\begin{tabular}{|c|c|c|c|}
\hline Process step & Purpose & RTEC & Bread \\
\hline Cleaning & To remove any dirt and debris & $\mathrm{x}$ & $\mathrm{x}$ \\
\hline Grading & Broken kernel pieces are separated from bran and cereal dust to ensure conformity in the output & $\mathrm{x}$ & $\mathrm{x}$ \\
\hline Parboiling & To loosen the hull and improve the storage stability & $\mathrm{x}$ & $x$ \\
\hline Soaking & To condition the grains for downstream steps & $\mathrm{x}$ & $\mathrm{x}$ \\
\hline Hulling & Removal of the outer inedible hull leaving the bran, germ and endosperm & $\mathrm{x}$ & $\mathrm{x}$ \\
\hline Tempering & $\begin{array}{l}\text { A process whereby water is added to clean wheat and allow equilibration throughout the kernel. It aims to make it } \\
\text { easier to separate the bran from the endosperm (flour) and to yield a flour close to the desired moisture content }\end{array}$ & $\mathrm{x}$ & $\mathrm{x}$ \\
\hline Grinding & A gradual reduction process to begin separation of the germ, brand and endosperm & $\mathrm{x}$ & $\mathrm{x}$ \\
\hline Milling, pounding & $\begin{array}{l}\text { Process of making cereals into flour. Milling can be wet or dry whereby wet milling is usually applied with the main } \\
\text { focus on yielding starch and gluten, while dry milling separates the outer layer (bran), from germ and endosperm }\end{array}$ & $\mathrm{x}$ & $\mathrm{x}$ \\
\hline Cooking & To transform the hard kernel to a soft mass, increasing digestibility of nutrients & $\mathrm{x}$ & $\mathrm{x}$ \\
\hline Drying & To ensure appropriate moisture content for next processing steps & $\mathrm{x}$ & $\mathrm{x}$ \\
\hline Fermentation & $\begin{array}{l}\text { Micro-organisms are applied to the dough to achieve sensory attributes and improve digestibility by enzymic } \\
\text { breakdown of oligosaccharides and reduction in non-nutrients such as phytates, tannins and polyphenols }\end{array}$ & & $\mathrm{x}$ \\
\hline Baking & It causes the outer surface to brown (Maillard reaction), influencing taste and appearance & $\mathrm{x}$ & $\mathrm{x}$ \\
\hline Puffing & $\begin{array}{l}\text { To expose the cereals to very high steam pressure causing the cereal to burst. Puffed cereals may be further } \\
\text { toasted, coated or mixed with other ingredients }\end{array}$ & $\mathrm{x}$ & \\
\hline Flaking & $\begin{array}{l}\text { To prepare partially cooked formulations into quick-cooking or ready-to-eat foods. Typically, cereals are softened by } \\
\text { partially cooking in steam, followed by pressing or rolling into flakes which are dried }\end{array}$ & $\mathrm{x}$ & \\
\hline Extrusion & To mould the dough into the desired shape by heating the dough and forcing it through a small hole & $\mathrm{x}$ & \\
\hline Coating & To apply vitamins and minerals as well as flavours including cocoa, chocolate, nuts, sugars and oils & $\mathrm{x}$ & \\
\hline Toasting & To achieve attributes of the finished product with particular reference to consumer acceptability & $\mathrm{x}$ & $\mathrm{x}$ \\
\hline
\end{tabular}

* Depending on the desired product, not every step will necessarily be involved in the manufacture of breads or RTEC.

evident that the majority of generic processes for making a wheat-based flaked RTEC or bread are very similar (Table 1). Notable differences do exist such as fermentation for bread or steps like puffing, flaking, roasting or batch cooking which are applied to RTEC, or steps like extrusion to achieve the desired product characteristics. Extrusion is not applied in bread making (Table 1). One additional step which can be common to both cereal products involves the addition of vitamins and/or minerals to the mix or blend either as a restorative function to replace losses during extraction or as fortificants. We acknowledge that there are of course many variations to processing steps not only depending on the final product characteristics but also types of cereals used as raw materials. For example, traditional milling of oats first requires a thermal treatment to inactivate endogenous enzymes and prevent rancidity, followed by dehulling (dry-shelling) ${ }^{(41)}$. The more modern 'green-shelling' process, however, requires the oats to be shelled before kiln-drying ${ }^{(42)}$. Furthermore, the nature of the endproduct will define which processes can be applied, for example, shredded cereals require different processing steps to the flake cereals described here. Nevertheless, when comparing the generic processing steps for wheat bread and flaked RTEC as illustrated here, it is evident that considerable similarities exist, with thirteen of the seventeen generic processing steps common to wheat-based bread and RTEC (Table 1).

Impact of processing on the nutrient and non-nutrient composition of bread and ready-to-eat breakfast cereals

The nutritional composition of the main types of whole cereal grains consumed by humans is shown in Table 2 . In general, raw whole grains contain typically about $60-80 \%$ carbohydrate along with some fat and protein. Whole cereal grains also contain considerable levels of many nutrients and non-nutrients due to the presence of functional molecules, dietary fibre, minerals, vitamins, lignans, phyto-oestrogens and phenolic compounds in their outer layers (bran, germ and endospermic tissue) ${ }^{(43)}$. Furthermore, whole-grain products contain more vitamins and minerals than their refined-grain counterparts. Processing of cereals and the associated removal of outer layers can alter their nutritional value; however, there are more facets to processing. The following subsections highlight the impact on composition following processing of cereals to bread and RTEC in more detail. Table 3 provides an overview of how the nutrient and non-nutrient composition may be altered during the manufacture of RTEC and bread and is described in brief below for energy and macronutrients and in the 'Impact on micronutrients and non-nutrient compounds' section.

\section{Impact on energy and macronutrient content}

The endosperm, the large central part of the grain, is mostly composed of carbohydrates in the form of starch. Hence with milling and subsequent removal of the grain's fibre fraction, this main constituent of cereals (starch) can become more easily accessible and digestible ${ }^{(44)}$ and can lead to an increased glycaemic response following hydrolysis in the upper gastrointestinal tract. Only a fraction of starch in foods is not digested and absorbed in the small intestine, reaching the colon, where it is fermented to a variable extent by the microbiome. This fraction is called resistant starch. Resistant starch acts as a type of dietary fibre and has the ability to contribute to a healthy gut microbiota as described elsewhere $^{(45-47)}$.

All cereals used to make RTEC and breads undergo milling to various extents (for example, whole grain, refined grains) and so 
Table 2. Nutritional composition of different whole grains and refined grains (per $100 \mathrm{~g}$ )*

\begin{tabular}{|c|c|c|c|c|c|c|}
\hline Nutrient & $\begin{array}{l}\text { Wheat flour } \\
\text { (whole grain) }\end{array}$ & $\begin{array}{l}\text { Wheat flour } \\
\text { (refined) }\end{array}$ & $\begin{array}{l}\text { Rice flour } \\
\text { (brown) }\end{array}$ & $\begin{array}{l}\text { Rice flour } \\
\text { (white) }\end{array}$ & $\begin{array}{l}\text { Maize flour, yellow } \\
\text { (whole grain) }\end{array}$ & $\begin{array}{c}\text { Maize flour, yellow } \\
\text { (refined) }\end{array}$ \\
\hline Carbohydrates (g) & 75 & 76 & 75 & 80 & 77 & 83 \\
\hline Protein $(\mathrm{g})$ & 10 & 10 & 7 & 6 & 7 & 6 \\
\hline Fat $(\mathrm{g})$ & 2 & 1 & 3 & 1 & 4 & 1 \\
\hline Dietary fibre (g) & 13 & 3 & 5 & 2 & 7 & 2 \\
\hline \multicolumn{7}{|l|}{ Vitamins } \\
\hline Thiamin (mg) & 0.3 & 0.1 & 0.4 & 0.1 & 0.2 & 0.07 \\
\hline Riboflavin (mg) & 0.2 & 0.04 & 0.1 & 0.02 & 0.1 & 0.06 \\
\hline Niacin (mg) & $5 \cdot 3$ & $1 \cdot 3$ & $6 \cdot 3$ & 3 & 1.9 & 2.7 \\
\hline Pyridoxine (mg) & 0.2 & 0.04 & 0.7 & 0.4 & 0.4 & 0.1 \\
\hline Folate $(\mu \mathrm{g})$ & 28 & 26 & 16 & 4 & 25 & 48 \\
\hline \multicolumn{7}{|l|}{ Minerals } \\
\hline $\mathrm{Fe}(\mathrm{mg})$ & 3.7 & $1 \cdot 2$ & $2 \cdot 0$ & 0.4 & 2.4 & 0.9 \\
\hline $\mathrm{Zn}(\mathrm{mg})$ & 3.0 & 0.7 & 2.5 & 0.8 & $1 \cdot 7$ & 0.4 \\
\hline $\mathrm{Mg}(\mathrm{mg})$ & 117 & 22 & 112 & 35 & 93 & 18 \\
\hline $\mathrm{Na}(\mathrm{mg})$ & 3.0 & 2.0 & 8 & 0 & 315 & 1 \\
\hline
\end{tabular}

* Obtained from the United States Department of Agriculture nutrient database ${ }^{(127)}$.

Table 3. Overview of the influence of some processing steps on nutrient and non-nutrient content, highlighting steps in the manufacturing of ready-to-eat breakfast cereals (RTEC) and bread(26,29,44,48-50,56-61)

\begin{tabular}{|c|c|c|}
\hline Processing step & Effect on nutrient content & $\begin{array}{c}\text { Effect on non-nutrient } \\
\text { content }\end{array}$ \\
\hline \multicolumn{3}{|c|}{ Primary processing } \\
\hline $\begin{array}{l}\text { Soaking/ } \\
\text { germination }\end{array}$ & & $\downarrow$ Phytic acid \\
\hline Milling* & $\begin{array}{l}\downarrow \text { Fibre, minerals, some } \\
\text { vitamins } \\
\uparrow \text { Digestible carbohydrates }\end{array}$ & $\downarrow$ Polyphenols, tannins \\
\hline \multicolumn{3}{|c|}{ Secondary processing } \\
\hline $\begin{array}{l}\text { Flaking } \\
\text { (RTEC) }\end{array}$ & $\begin{array}{l}\downarrow \mathrm{P} \text { and fibre } \\
\leftrightarrow \mathrm{Fe} \text { and } \mathrm{Ca} \text { (rice cakes) }\end{array}$ & \\
\hline $\begin{array}{l}\text { Fermentation } \\
\quad \text { (bread) }\end{array}$ & & $\begin{array}{l}\uparrow \text { Phenolics } \\
\downarrow \text { Phytic acid (with } \\
\text { hydrothermal } \\
\text { treatment) }\end{array}$ \\
\hline $\begin{array}{l}\text { Heat- } \\
\text { treatments }\end{array}$ & $\begin{array}{l}\downarrow \text { Lysine (protein) content } \\
\uparrow \text { Resistant starch } \\
\leftrightarrow \text { Fibre, iodine } \\
\leftrightarrow \text { Mineral bioavailability, } \\
\quad \text { vitamin retention }\end{array}$ & $\uparrow$ Ferulic acid \\
\hline Extrusion & $\begin{array}{l}\text { Redistribution from insoluble } \\
\text { to soluble fibre }\end{array}$ & \\
\hline Fortification & $\begin{array}{l}\uparrow \text { To restore lost nutrients } \\
\text { (thiamin, niacin, Ca, Fe) } \\
\uparrow \text { To act as a fortificant } \\
\text { (not limited to niacin, } \\
\text { thiamin, riboflavin, vitamin } \\
\text { D, vitamin K, vitamin A, } \\
\text { Zn, Fe) }\end{array}$ & \\
\hline
\end{tabular}

* Typically including fractionation.

final quantities of energy and macronutrients present are more influenced by the extent of milling and extraction rather than belonging to a particular commodity group. Cereals also contain protein and fat in addition to carbohydrates, but this is relatively less than other dietary staples, for example, dairy products or meat. Nevertheless, macronutrient composition can be affected by the level of processing. For one example, as part of the Maillard reaction the essential amino acid lysine has been described to become potentially unavailable when the dough is heated in the presence of reducing sugars, thereby altering protein amino acid profile ${ }^{(48)}$. This would make an argument for using whole grains as the cereal source, because whole grain contains more protein than refined grain.

\section{Impact on micronutrients and non-nutrient compounds}

Although nutrients are found to varying degrees throughout the cereal, there is a higher concentration of micronutrients and fibre in the bran. Polyphenols such as ferulic acid or cinnamic acid are also present mainly in the outer layers of cereal bran, but phytosterols are reported to accumulate in both the bran and germ fractions ${ }^{(49)}$. Hence, removal of the bran fraction during the primary processing step, milling, can result in reductions in a number of nutrients and non-nutrients present, for example, dietary fibre, tannins, polyphenols, minerals and some vitamins ${ }^{(50)}$, the concentration of nutrients decreasing with the degree of milling $^{(51)}$. For example, Oghbaei \& Prakash ${ }^{(52)}$ reported a loss of vitamins in the range of $70-80 \%$ when rice is milled. Alterations in dietary fibre composition and content will also depend on the level and type of processing and affect both soluble (for example, $\beta$-glucans) and insoluble forms (for example, arabinoxylans $)^{(49)}$. Although bran fibre can be added back in later as an ingredient, such losses may provide an argument to prefer whole-grain products or products with added bran fibre over refined-grain products. In contrast, the presence of naturally occurring inhibitors in whole grains such as phytic acid can render the bioavailability of divalent minerals (for example, $\mathrm{Fe}, \mathrm{Zn}$ or $\mathrm{Ca}$ ) low because of the formation of insoluble complexes $^{(53)}$. However, phytic acid has also been recognised as a natural antioxidant ${ }^{(54)}$ which may potentially explain the protective effect of whole grain for colorectal cancer ${ }^{(55)}$. Hence, the 'right' amount and method of processing can reduce or prevent this anti-nutritional activity ${ }^{(49)}$ and perhaps confer protection for colonic health.

As mentioned, secondary processing techniques generally involve heat in some manner and are used to 'add value to goods' 
or variety to the diet. As evident in Table 3, the impact on nutrient and non-nutrient content is often dependent on the individual processing technique and while some are common to breads and RTEC, others are commodity and product specific. For example, the process of flaking has the potential to alter the content of $\mathrm{P}$ and dietary fibre but not Fe and $\mathrm{Ca}$ : using rice flakes as a medium, fibre and $\mathrm{P}$ content decreased in proportion to the thickness of the flakes, while Fe and Ca contents were reported as unaffected ${ }^{(56)}$. In contrast, the process of fermentation in bread making (used to break down the tough outer hulls and increase cereal digestibility) may increase the content of phenolic compounds and enhance bioavailability ${ }^{(57)}$. Furthermore, fermentation in combination with hydrothermal treatment and particle size reduction has been shown to reduce phytic acid ${ }^{(58)}$, which in turn could increase the availability of minerals that are otherwise bound by phytic acid. Fermentation is widely used in bread making. Other processes like soaking and germination reduce the phytic acid content in cereals ${ }^{(59)}$. Extrusion seems to have no effect on mineral bioavailability ${ }^{(60)}$ or retention of vitamins, respectively ${ }^{(26)}$. Another important mineral, iodine, appears relatively stable throughout the process chain, as it was retained to $100 \%$ in the final products when applied as salts ${ }^{(61)}$. Salt is a key vehicle for fortification in some countries. Ferulic acid is the most abundant phenolic acid in wheat. There is evidence that ferulic acid increase up to 3 -fold ${ }^{(26)}$, while others point to the potentially increased antioxidant activities rather than content ${ }^{(51,62)}$.

Cooking forms a central process for both RTEC and bread making, with cooking increasing the digestibility of nutrients and functional molecules ${ }^{(48)}$. Dietary fibre has been shown to be relatively resistant to heat treatment ${ }^{(63)}$. The content of dietary fibre is hardly affected by extrusion cooking but a redistribution of insoluble to more soluble fractions has been reported ${ }^{(29)}$ and increases with the intensity of the process conditions ${ }^{(64)}$. In addition, the content of resistant starch may be influenced by cooking processes. For example, a form of resistant starch called retrograded starch may be increased by the heat treatment and subsequent cooling ${ }^{(48)}$. Optimal parameters for increasing this retrograded (resistant) starch in specific products, such as actual temperature, cooling temperature and duration of those steps, are not yet clearly defined. In addition, hydration may also affect the formation of resistant starch, by reducing its content. This is also true, in terms of extrusion cooking, where starch becomes fully gelatinised, resulting in a possible decrease in molecular entanglement and reduced resistant starch formation compared with other processing methods ${ }^{(65)}$. Approaches to modify the composition of resistant starch in products have been described elsewhere ${ }^{(66)}$. Building on the point of replacing digestible starch with resistant starch, it has been demonstrated that processing techniques such as roasting, baking and boiling increased the content of resistant starch in cereal products, whereas steaming and frying had the opposite effect ${ }^{(65)}$. Also, the storage of different cereal products at $4^{\circ} \mathrm{C}$ up to $24 \mathrm{~h}$ significantly increased resistant starch content.

The ability of resistant starch to contribute to a healthy gut microbiota has been described in detail elsewhere ${ }^{(46,47)}$. Another key consideration relates to fortification. In countries where fortification is permitted, both RTEC and breads can contribute substantially to the intakes of certain nutrients. A final step in many bread-making steps is the addition of micronutrients to white flours either to restore those lost during extraction (restorative function) or as fortificants. For example, under UK law, white flours must be enriched with thiamin, niacin and $\mathrm{Ca}$ to combat nutrient losses in extracted white flours and to ensure minimum levels of these nutrients in the $\operatorname{diet}^{(67,68)}$. In the USA, thiamin, Fe and niacin must be added and since 1998 folic acid in a bid to reduce the occurrence of neural tube defects. Although no European countries currently fortify breads with folic acid, this is common in many other countries globally ${ }^{(69)}$. In contrast, RTEC, when fortified, may contain considerably greater numbers of vitamins and/or minerals and it is recognised that RTEC are one of the most highly fortified foods, helping to improve the overall nutritional status of consumers ${ }^{(70)}$. Their consumption with milk and milk products can also enhance nutritional intakes at meal times for key nutrients such as $\mathrm{Ca}$, vitamin $\mathrm{D}$ (if fortified), riboflavin and $\mathrm{K}^{(71)}$.

Collectively, such processing techniques can increase or decrease the amounts and accessibility of a number of macroand micronutrients in the two cereal products examined, even within categories. For example, using UK food composition data, consuming a breakfast consisting of one $40 \mathrm{~g}$ bowl of wholegrain fortified RTEC (for example, wheat biscuits, no milk) and two average slices of whole-grain bread (plain) would yield $293 \mathrm{kcal}$ (1226 kJ), $60 \mathrm{~g}$ carbohydrates, $9 \cdot 1 \mathrm{~g}$ fibre, $10 \cdot 2 \mathrm{mg}$ niacin, $318 \mathrm{mg}$ $\mathrm{K}$ and $3.6 \mathrm{~g}$ of total sugars. On the other hand, choosing a fortified sugar-containing RTEC (for example, 35 g extruded type cereal, no milk) with white bread results in intakes of $297 \mathrm{kcal}(1243 \mathrm{~kJ})$, $64 \mathrm{~g}$ carbohydrates, $3.7 \mathrm{~g}$ fibre, $7.6 \mathrm{mg}$ niacin, $175.8 \mathrm{mg} \mathrm{K}$ and $14.4 \mathrm{~g}$ of total sugars. Although energy profiles are similar, distinct differences with respect to fibre and some micronutrients exist. Simplistically, this implies that choice of products consumed over prolonged periods of time has significant potential to impact nutrient intakes at both an individual and population level, with healthier options available and needed across all categories to help individuals and populations meet dietary guidelines.

In conclusion, depending on the extent of primary and secondary processing steps involved, the final nutritional value of the by-products can vary greatly. While some common processes (for example, milling and refining) reduce the vitamin and mineral content of cereal, they can also enhance bioavailability of some nutrients as well as the digestibility and accessibility of phenolic compounds. Further, strategies can be employed to mitigate any risk of nutrient losses, for example, to choose whole-grain and bran-based products over refinedgrain products, to use the processes of soaking, fermentation and germination to increase mineral bioavailability and reduce phytic acid content. Also, the addition of vitamins and/or minerals (restorative or fortification) will increase nutrient content. Collectively this suggests that by eating a wide variety of foods, as recommended as part of food-based dietary guidelines, we can benefit from a mix of nutrients which are bioavailable in different food forms. It also shows that there are no real differences in losses of nutrients depending on processing of the two major cereal types; both processes are similar. 
The role of processing for safety in cereal-based food products

Generally, a fundamental reason for processing is food safety. Raw, unprocessed cereal grains can represent a substantial source of natural contaminants, specifically mycotoxins and heavy metals ${ }^{(72)}$, with contaminants heterogeneously distributed within the kernel ${ }^{(73)}$. Mycotoxins are poisons produced by fungi or can be toxins produced by moulds. There are many different mycotoxins that have been commonly found to contaminate cereal grains; these include aflatoxins, ochratoxin, fumonisins, deoxynivalenol, T-2 toxin, zearalenone and alkaloids. It has been pointed out that processing of cereal contributes to a substantial reduction in contaminants ${ }^{(74)}$, where any risk to human safety is greatly lessened. In particular, large fractions of mycotoxins can be removed by appropriate post-harvest storage, sorting, cleaning, dehulling, and debranning reduction of damaged kernels, and fine material ${ }^{(75)}$. These are processes common to cereals used for RTEC and bread. In addition, it has been suggested that the $\mathrm{Se}, \mathrm{Mg}, \mathrm{Ca}, \mathrm{Zn}, \mathrm{Fe}$ and dietary fibre, inherent in whole-grain RTEC and bread may have protective properties by reducing uptake and toxicity of heavy metals ${ }^{(76)}$. Whole-grain products with high levels of antioxidants, vitamins and carotenoids as well as superoxide anion scavengers, such as ferulic acid in whole-grain wheat, have the potential to reduce the impact of mycotoxins by protecting cell membranes from mycotoxin-induced damage ${ }^{(76)}$. Novel food processing techniques have been invented to further improve nutritional quality and advance production efficiency, while ensuring microbial safety. Grain-based foods can also become contaminated with plant toxins, for example, alkaloids or tropane alkaloids, but typically this is as a result of cross-contamination with toxin-containing plants rather than being integral to the grain itself. Processing to ensure safety of cereal-based products is predicted to become increasingly important in the context of climatic change, drive to organic sustainable farming and desire to abandon the use of chemicals in farming ${ }^{(77)}$. Other examples of common toxins in food and present in the diet of most individuals are the process contaminants furan and acrylamide. The formation of both is linked to the Maillard reaction. This reaction enhances the taste of the cooked food items and often adds to the brownish colour of foods.

The formation of acrylamide relies on the presence of carbohydrates (reducing sugars such as glucose and fructose) and the amino acid asparagine when cooked at high temperatures such as in frying, roasting, toasting and baking ${ }^{(78)}$. Therefore, a variety of food products including French fries (chips), potato crisps, bread, breakfast cereals (excluding porridge), fine bakery wares, coffee and coffee substitutes as well as 'baby food' and processed cereal-based food intended for infants and young children ${ }^{(79)}$ can be sources of acrylamide. Levels of acrylamide in products can range substantially and depend not only on processing but on growing conditions of the crops (i.e. cereal type, variety, growing conditions, climate) and methods used for analysis. The sourcing of wheat with lower free asparagine is currently not a viable option because it is commercially not available. Therefore, mitigation of acrylamide formation is mainly achieved through changes in product composition and/or process conditions. For example, extended fermentation time has been shown to result in dough with lower levels of acrylamide in bread ${ }^{(78)}$. EU authorities have provided effective mitigation measures as well as regulatory benchmarks for acrylamide levels in food products including RTEC (150-300 $\mu \mathrm{g} / \mathrm{kg})$ and soft bread $(50-100 \mu \mathrm{g} / \mathrm{kg})^{(80)}$. In comparison, the benchmarks for roast coffee is $400 \mu \mathrm{g} / \mathrm{kg}$, French fries $500 \mu \mathrm{g} / \mathrm{kg}$ and potato crisps $750 \mu \mathrm{g} / \mathrm{kg}$. The regulatory benchmarks are typically lower for bread and RTEC than for other commodities.

Furans are another class of contaminant, potentially formed in foods during thermal processing. The formation of furans requires several precursors such as ascorbic acid, amino acids, carbohydrates, unsaturated fatty acids and carotenoids, and they are found in a variety of foods including coffee and canned foods ${ }^{(81)}$. The presence of furans in the diet, and any implication for public health are closely monitored by the authorities. For example, in Europe, EFSA has characterised that grain and grain-based products are chief sources of furans in children, but not in adults. In adults, coffee is the main contributor of furans ${ }^{(82)}$. Mitigation strategies depend on the food product and include lowering the thermal load, and adding antioxidants that delay lipid oxidation ${ }^{(82)}$. However, specific mitigation strategies are still under investigation ${ }^{(82)}$.

Taken together, many of the core processes used to manufacture bread and RTEC can decrease the presence and/or amounts of contaminants, while best practices can mitigate the risk of forming any process-related undesired substances, for example, furans and acrylamide, thereby ensuring food safety.

\section{The roles of ready-to-eat breakfast cereals and bread for} the human diet

The contribution of processed foods in general, as defined by the International Food Information Council, to nutrient intake has been described ${ }^{(83)}$. For example, in 2014 the American Society for Nutrition reported that, for the USA, processed foods contributed $57 \%$ of energy, $55 \%$ of dietary fibre, $48 \%$ of Ca, $43 \%$ of K, $34 \%$ of vitamin D, $64 \%$ of Fe, $65 \%$ of folate and $46 \%$ of vitamin $\mathrm{B}_{12}$ intakes. On the other hand, processed foods contributed $52 \%$ of saturated fat, $75 \%$ of added sugars and $57 \%$ of $\mathrm{Na}$. Within this, the American Society for Nutrition concluded that the level of processing was of secondary priority as long as nutrient-dense foods are selected ${ }^{(83)}$.

For RTEC and bread (both processed foods), their role as part of healthy balanced diets has been acknowledged ${ }^{(37,61,84-86)}$. For both foods, options that are made with whole grain and are high in fibres makes them a valuable source of key nutrients such as vitamins and minerals, antioxidants ${ }^{(85,87)}$ and other plant actives $^{(37,88)}$. Therefore, whole grain should be the preferred option; however, in reality, although the available choices of whole-grain foods are increasing globally, the majority of bread and RTEC are still consumed as refined grain.

\section{Contribution to nutrient intakes}

Both RTEC and bread make significant contributions to population nutrient intakes. Healthy adult habitual breakfast cereal 
consumers are reported to have a higher proportional intake of energy from carbohydrates and lower intake of total and saturated fats than non-consumers ${ }^{(71,86)}$. Further, consumption of breakfast cereals has been associated with healthier dietary patterns in adults and children ${ }^{(71)}$ and to increase intake of associated foods such as milk and fruit ${ }^{(89)}$. Portion sizes associated with such benefits are typically moderate, for example, in a European cohort the average portion size of cereals consumed by adolescents was 35 (interquartile range $24-56$ ) $\mathrm{g}^{(89)}$; this RTEC-consuming group also reported lower intakes of energy and fat but higher protein, carbohydrate and fibre when compared with adolescents consuming mostly bread for breakfast. Inclusion of RTEC in the diet may also yield higher intakes of vitamins and minerals and lower fat intakes but without influencing intakes of energy or $\mathrm{Na}^{(71,90,91)}$. In particular, frequent consumption of RTEC ( $>5$ times per week) has been associated with a lower risk of inadequate intakes of vitamin $\mathrm{A}, \mathrm{Ca}$, folate, vitamin $\mathrm{B}_{6}, \mathrm{Mg}$ and $\mathrm{Zn}$. However, the nutritional merits of some RTEC have been questioned because of the content of sugar, salt and saturated fat in some products ${ }^{(92)}$, while RTEC consumption was also found to be associated with higher sugar intake $\mathrm{e}^{(71)}$. Against this context, it is worth remembering that total dietary sugar intake will also be influenced by the intake of naturally occurring milk sugars following consumption of RTEC with milk, while the salt and added sugar composition of RTEC has decreased over the last decade ${ }^{(92)}$. On the other hand, RTEC can act as an important source of whole grain and fibre ${ }^{(93)}$, with some products providing about $50 \%$ of its ingredients as whole grain. RTEC also have a substantial contribution to people's nutrient intake; for example, in France, with a relatively low consumption of breakfast cereals, the overall contribution of breakfast cereals at breakfast alone is $14.7 \%$ of energy, $19.2 \%$ of carbohydrates, $7.9 \%$ of protein, $20.3 \%$ of fibres, $10.5 \% \mathrm{Ca}$ and $33 \% \mathrm{Fe}^{(94)}$. However, in Canada, a country with a relatively high consumption of breakfast cereals, for an adult cohort, $9.3 \%$ of the daily energy was reported from RTEC, this category also contributing $15.3 \%$ carbohydrates, $5.7 \%$ protein, $22.7 \%$ fibres, $5.5 \% \mathrm{Ca}$ and $32.2 \%$ Fe to the daily intake of these nutrients ${ }^{(95)}$.

For bread, it is reported that EU citizens consume approximately $50 \mathrm{~kg}$ of bread per person per year or about three to four slices of white bread per d, with citizens of Germany and Austria consuming slightly more and those of the UK and Ireland less ${ }^{(96)}$. Outside of the UK (where vitamins and minerals are re-added to white flour after milling), breads made with whole-grain flours will generally yield a higher composition of fibre and vitamins (for example, thiamin, niacin, folate) and minerals (for example, $\mathrm{Fe}, \mathrm{Zn}$ and $\mathrm{Mg})^{(37)}$. However, the exact contribution will depend on the type of flour used ${ }^{(86,96)}$. For example, in the UK, total bread is reported to contribute approximately $12 \%$ of total daily energy intake, $16-20 \%$ of carbohydrate, $10-12 \%$ of protein, up to $21 \%$ of fibre intakes, $12-17 \%$ of total $\mathrm{Ca}$ and $15-17 \%$ of total $\mathrm{Fe}$ intakes $^{(97)}$ (although the bioavailability of Fe powdered to fortify flour has been debated) ${ }^{(98)}$. Similar contributions are reported for France, where bread contributes to $15.5 \%$ of daily energy intake, $27.2 \%$ of carbohydrates, $2.7 \%$ of fat, $20.3 \%$ of fibres, $3.5 \%$ of $\mathrm{Ca}$ (only non-fortified sources) and $14.4 \%$ of Fe to the daily intake of these nutrients ${ }^{(99)}$.
Some health benefits of eating ready-to-eat breakfast cereals and bread

There is a significant body of evidence researching the influence of RTEC and various health outcomes ${ }^{(91)}$. For example, breakfast cereals have been reported to help lower cholesterol concentrations or improve bowel function, if high in oat, barley or fibre, respectively ${ }^{(91)}$. Despite concerns that presweetened breakfast cereals could increase the risk of overweight and obesity in children, this is not supported by current reviews ${ }^{(91)}$. Such effects (positive or negative) primarily relate to the composition of the foods (nutrient or otherwise), with the role for processing simply to make healthy choices as palatable as possible. For bread, specifically wheat bread and wheat products, there have been concerns linking wheat products (as part of a Western diet and lifestyle) and increasing prevalence of obesity, type 2 diabetes, allergy and food intolerances ${ }^{(100)}$. Such views have been particularly popular in the press and media and are despite scientific reviews to the contrary ${ }^{(100)}$. There are also suggestions that modern bread wheat has different health benefits from traditional wheat types, but again there is, to date, insufficient evidence to confirm this theory ${ }^{(101)}$. Nonetheless, the consumption of bread, particularly whole-grain bread has been linked with reduced mortality ${ }^{(102)}$.

For both RTEC and bread, it is likely that the benefits arise from the composition of the grains and the nutrients and nonnutrients contained within the matrix. For example, benefits with respect to cholesterol or postprandial glucose concentrations may relate to the presence of $\beta$-glucans with associated health claims approved in Europe by the EFSA ${ }^{(103)}$. Also, given that both foods can contain considerable amounts and types of dietary fibre, not least, arabinoxylan, resistant starch and lignin, this can have benefits with respect to gut health and can influence glycaemic response ${ }^{(37)}$. Specifically, resistant starch has been consistently shown to reduce the glycaemic response, which resulted in an approved EFSA health claim ${ }^{(47)}$. Furthermore, EFSA also acknowledges health benefits of wheat bran fibre ${ }^{(104)}$. On the back of considerable observational evidence showing that individuals who consume more whole grain have a lower risk of chronic disease ${ }^{(105)}$, this has encouraged countries/agencies to issue dietary intake recommendations for whole-grain options of both these processed dietary staples in an effort to improve diet quality and enhance health ${ }^{(105)}$

\section{Challenges of defining cereal-based products by level of processing}

Current debate suggests grouping foods by level of processing ${ }^{(17)}$. In analyses of diet and health, grouping of foods and/or nutrients is common and has a strong historic background. For example, food groups are central to population dietary advice as part of food-based dietary guidance or as more complex food categorisations or coding systems within the scientific literature. There are many well-established examples of such coding systems, for example, the Langual (Langua alimentaria) system (first developed by the US Food and Drug Administration in the 1970 s and which has since been modified 
and adopted by the EU consortium, Eurofir $\left.{ }^{(106,107)}\right)$ and systems created by EFSA (Food Ex) ${ }^{(108)}$ and the European Prospective Investigation into Cancer and Nutrition (EPIC) Consortium ${ }^{(109)}$. Within these generally faceted systems comprehensive information on food descriptors is gathered, not least food source, cooking method, ingredients, use of fortificants and preservation technique (i.e. including some account of processing). Such coding systems are used to account for processing both with respect to influence of processing on exposure to food chemicals ${ }^{(108)}$ or the role of nutrients or phytochemicals on disease risk $^{(109)}$.

Nevertheless it has been argued that the significance of processing and potential impact on health has been underestimated $^{(16,17)}$ and hence alternative categorisations or descriptors have been developed which depend solely on the level of processing. For example, that of the International Food Information Council ${ }^{(9)}$ which relates to five categories of processing (1) minimally processed, (2) processed to preserve or enhance nutrients or freshness, (3) combining foods with ingredients to enhance sensory and/or safety appeal, (4) ready-to-eat foods, (5) foods packaged to stay fresh and save time or the NOVA categorisation ${ }^{(16,17)}$ where foods can be divided into four categories (1) unprocessed and minimally processed, (2) processed culinary ingredients, (3) processed foods, (4) ultra-processed foods. Confusingly, depending on which categorisation scheme is used, a food may be listed as processed in one scheme but highly or ultra-processed using another coding system. There is currently no scientific consensus on how processing should be addressed as part of food coding systems, particularly with respect to method of processing (traditional, novel), number of ingredients, use of legally permitted food additives, etc. While such debate continues, it is unclear how this information can be used to scientifically measure trends in dietary quality or the relationship of diet with chronic disease ${ }^{(10,110)}$. Further, it is unclear how such newer categorisation systems satisfy the generally accepted principles underpinning general population dietary guidance are that they should be understandable, actionable, affordable and safe ${ }^{(14)}$. There may be learnings on those principles from the French dietary guidelines, which recently discouraged the consumption of ultraprocessed foods ${ }^{(111)}$. As identified elsewhere, any shift in the use of food coding systems, particularly in studies relating to states of health or ill-health, should be accompanied by objective validation, use of biomarkers where possible and careful interpretation of results ${ }^{(112)}$.

Finally, consideration must also be given to how such newer categorisation systems are communicated beyond scientific audiences. Consumer insights suggest that simple and realistic nutrition messages are welcome ${ }^{(113)}$, and such new initiatives have led to economic opportunities for the development of phone-based applications and the creation of commercial companies (for example, https://siga.care/). However, given that there is no agreed consensus globally on ways to categorise foods such as cereals according to level of processing or more critically how any such categorisation could impact population dietary behaviour, care must be exercised to avoid confusion and distrust among consumers and to avoid any decreases in intakes of key nutrients which cereal products can provide, including those from fortified products.

\section{Future considerations}

An increasing focus of consumers as well as of public health authorities is sustainable diets. Indeed, the notion of shifting current dietary patterns towards more sustainable systems that carry environmental as well as health benefits has been favoured by the FAO as part of their 2010 definition of sustainable diets ${ }^{(114)}$. Sustainability aspects have since been included in national dietary guidelines by countries such as Sweden ${ }^{(115)}$, Brazil ${ }^{(116)}$ and the Netherlands ${ }^{(117)}$ with mention of similar discussions in the $\mathrm{UK}^{(118)}$. Parallel with this background of sustainability is forecasted world population growth, estimated to reach approximately 9.2 billion in $2050^{(119)}$. Therefore, the world faces the challenge to meet increasing demands of key nutrients but in a sustainable manner. Food processing has traditionally represented an important link between production and consumption of food. In order to provide healthy diets and a maintainable food supply for an ever-growing population, all food processors (including those of grain products) must also consider the challenge of sustainable diets as a matter of concern and action.

Cereals, particularly whole grain, are nutrient-dense. They provide energy as well as significant contributions to population intakes of carbohydrate, protein, fibre and many micronutrients. This is often by virtue of their frequent consumption by large segments of the population. For example, in the UK, white bread, although containing about $155 \mathrm{mg} \mathrm{Ca} / 100 \mathrm{~g}$ contributes approximately $12-17 \%$ to population Ca intakes, particularly in groups such as children and adolescents ${ }^{(120)}$. Hence, all cereals need to be regarded in helping meet increased demands for these key nutrients globally.

However, the environmental impacts of RTEC or bread and their role as part of future sustainable diets have not been assessed broadly in scientific papers. One paper, using the Dutch diet as the basic setting, applied a model comparing bread and RTEC, as well as dairy products and meat between 0 and $250 \%$ of the current intake with the relationship between the quantity of these food products and the environmental impact as well as the nutrient balance of these diets examined ${ }^{(121)}$. The authors found that RTEC and bread had a better environmental performance compared with dairy products or meat while still maintaining a high nutrient balance. Others assessed the influence of breakfast cereal production on land use and biodiversity; they identified cocoa cultivation as a major contributor to the loss of biotic production ${ }^{(112)}$, with maize and rice representing further factors. Also, using life-cycle assessment tools, the environmental impact of breakfast cereals, limited to breakfast cereals produced by Kellogg's Europe, has been explored. Given the small quantities of cocoa across all Kellogg's Europe breakfast cereals ( $<5 \%$ by mass), the finding underpins the substantial impact of the use of cocoa in all food manufacturing, considering that cocoa is used in a variety of food categories other than RTEC $^{(122)}$. When it comes to assess sustainability of diets/food groups, the whole life cycle of a product, including, for example, packaging and distribution of products, needs to be considered. 
A comparison between the traditional ('bag-in-box' packages) and loose delivery (low-density polyethylene) revealed a potential of up to $85 \%$ waste reduction ${ }^{(123)}$. However, boxes may serve many purposes and the choice of bag material to ensure consistent quality and safety of the products also needs to be taken into account. An interesting approach to further improve the carbon footprint of RTEC and bread, while maintain or increasing nutrient balance scores, involves the replacement of refined flours by pulses ${ }^{(124)}$. When combining carbon footprint and nutrition into one score, the authors showed that yellow pea flour decreased the nutrition carbon footprint score by $15 \%$ for pan bread and $90 \%$ for breakfast cereal. This example for cereal-based food shows that there are opportunities to improve carbon footprint and nutrition value simultaneously.

To address the above demands the EAT-Lancet Commission suggests optimising diets for sustainable food systems predominantly by a shift of diets to plant-based diets ${ }^{(125)}$. Naturally, there are considerable challenges in shifting populations' diets in this direction, costs of fruit and vegetables being one. Cereals already contribute significantly to the energy supply globally, and they can and should play a more dominant role in providing energy and nutrients in a sustainable way to meet demands for increasing global population.

\section{Summary}

Cereals have been consumed by humans since approximately 100000 years ago. Cereals have to be processed in some way in order to be consumed by humans. Cereal processing is one of the oldest and given the role of cereals for its contribution to meeting nutrition requirements, one of the most important food technologies. Over the centuries, just like in any other food category, processing technologies have evolved in order to ensure safe products. Modern processes for RTEC and bread are efficient in providing sufficient products of good quality and to meet consumer expectations by providing a range of cereal foods that allow for a safe, varied and balanced diet. RTEC and bread share fundamental primary processing steps and many of the secondary processing steps. Potential reduction of nutrients can partly be balanced by choosing whole-grain varieties over refined-grain products as well as by fortification. On the other hand, processing enhances digestibility and bioavailability (for example, for minerals and phenolic acids) as well as reducing non-nutrients like phytic acid and contaminants. Based on the available scientific evidence to date and in comparison with more traditional approaches, the level of processing alone does not appear to act as a useful measure for the healthfulness of foods. Clearly, RTEC and bread play an important role in human nutrition by delivering important nutrients and are positively linked with intake of dietary fibre, certain vitamins and minerals, especially when consumed as whole grain. Therefore, whole-grain options should be the preferred choice. Cereal foods are part of the solution for sustainable diets as well as meeting the increasing global demand for energy and nutrients. From a public health perspective, it makes sense that food-based dietary guidelines in many countries already include cereal foods and specifically mention bread and breakfast cereals. It would be desirable to further strengthen the role of processed cereal foods by including more whole-grain, branbased and fibre-rich options and developing universally agreed quantitative recommendations for whole grain consumption.

\section{Acknowledgements}

The present review was supported by CEEREAL e.V. who had no role in the design, analysis or writing of this review.

F. T. and A. P. N. conceived the idea of this review paper. F. T., A. P. N. and J.-M. L. wrote the review. All authors read and approved the final version of the manuscript.

F. T. is consultant to CEEREAL e.V. and received research financial support for conducting the literature search and drafting the manuscript. A. P. N. and J.-M. L. declare no conflicts of interest.

\section{References}

1. Food and Agriculture Organization of the United Nations (2018) Crop prospects and food situation. Quarterly Global Reports. http://www.fao.org/3/CA2726EN/ca2726en.pdf (accessed September 2019).

2. Food and Agriculture Organization of the United Nations (2018) FAOSTAT: crops. http://www.fao.org/faostat/en/ \#data/QC (accessed June 2020).

3. Weiss E, Kislev ME, Simchoni O, et al. (2004) Small-grained wild grasses as staple food at the 23 000-year-old site of Ohalo II, Israel. Econ Bot 58, S125-S134.

4. Mercader J (2009) Mozambican grass seed consumption during the Middle Stone Age. Science 326, 1680-1683.

5. Revedin A, Aranguren B, Becattini R, et al. (2010) Thirty thousand-year-old evidence of plant food processing. Proc Natl Acad Sci U S A 107, 18815-18819.

6. Beetz KH (2020) Cereal Grains. Dictionary of American History https://www.encyclopedia.com/history/dictionariesthesauruses-pictures-and-press-releases/cereal-grains (accessed March 2020).

7. Augustin MA, Riley M, Stockmann R, et al. (2016) Role of food processing in food and nutrition security. Trends Food Sci Technol 56, 115-125.

8. Floros JD, Newsome R, Fisher W, et al. (2010) Feeding the world today and tomorrow: the importance of food science and technology. Compr Rev Food Sci Food Safe 9, 572-599.

9. International Food Information Council (2010) What is a Processed Food? You Might be Surprised! Understanding Our Food Communications Tool Kit. https://foodinsight. org/wp-content/uploads/2014/07/IFIC_Leader_Guide_high_ res.pdf (accessed September 2020).

10. Knorr D \& Watzke H (2019) Food processing at a crossroad. Front Nutr 6, 85.

11. van Boekel M, Fogliano V, Pellegrini N, et al. (2010) A review on the beneficial aspects of food processing. Mol Nutr Food Res 54, 1215-1247.

12. Welch RW \& Mitchell PC (2000) Food processing: a century of change. Br Med Bull 56, 1-17.

13. Grundy MM, Edwards CH, Mackie AR, et al. (2016) Re-evaluation of the mechanisms of dietary fibre and implications for macronutrient bioaccessibility, digestion and postprandial metabolism. Br J Nutr 116, 816-833.

14. Jones JM (2019) Food processing: criteria for dietary guidance and public health? Proc Nutr Soc 78, 4-18. 
15. European Food Safety Authority (EFSA) (2002) Regulation (EC) no 178/2002 of the European Parliament and of the Council of 28 January 2002 laying down the general principles and requirements of food law, establishing the European Food Safety Authority and laying down procedures in matters of food safety. http://eur-lex.europa.eu/LexUriServ/LexUriServ.do?uri=OJ: L:2002:031:0001:0024:EN:PDF (accessed September 2019).

16. Monteiro CA (2009) Nutrition and health. The issue is not food, nor nutrients, so much as processing. Public Health Nutr 12, 729-731.

17. Monteiro CA, Cannon G, Levy RB, et al. (2019) Ultraprocessed foods: what they are and how to identify them. Public Health Nutr 22, 936-941.

18. Rubel W (2011) Bread: A Global History. London: Reaktion Books Ltd.

19. Food and Agriculture Organization of the United Nations (2019) Post-harvesting processing. http://www.fao.org/3/aau104e.pdf (accessed September 2019).

20. European Food Safety Authority (EFSA) (2006) Commission regulation (EC) no 1881/2006 of 19 December 2006 setting maximum levels for certain contaminants in foodstuffs. https://eur-lex.europa.eu/legal-content/EN/ALL/?uri=CELEX \%3A32006R1881 (accessed December 2019).

21. Pétel C, Onno B \& Prost C (2017) Sourdough volatile compounds and their contribution to bread: a review. Trends Food Sci Technol 59, 105-123.

22. Gibney MJ, Barr SI, Bellisle F, et al. (2018) Towards an evidence-based recommendation for a balanced breakfast - a proposal from the international Breakfast Research Initiative. Nutrients 10, 1540.

23. Statista (2020) Breakfast cereals: worldwide. https://www. statista.com/outlook/40090100/100/breakfast-cereals/worldwide (accessed January 2020).

24. Akdogan H (1999) High moisture food extrusion. Int J Food Sci Technol 34, 195-207.

25. Campbell G \& Mateos-Salvador F (2008) Water and energy management in cereals processing. In Handbook of Water and Energy Managment in Food Processing, pp. 842-862 [J Klemeš, R Smith and J-K Kim, editors]. Sawston, Cambridgeshire: Woodhead Publishing.

26. Alam MS, Kaur J, Khaira H, et al. (2016) Extrusion and extruded products: changes in quality attributes as affected by extrusion process parameters: a review. Crit Rev Food Sci Nutr 56, 445-475.

27. Bartsch J (1990) Extrusion cooking. Herausgegeben von C. Mercier, P. Linko und J. M. Harper, 471 Seiten, zahlr. Abb. u. Tab., American Association of Cereal Chemists, Inc., St. Paul/Minnesota, USA, 1989, Preis: USA 89.-\$, im Ausland plus 10\%. Food/Nabrung 34, 264.

28. Harper JM (1978) Food extrusion. CRC Crit Rev Food Sci Nutr 11, 155-215.

29. Camire ME (1998) Chemical changes during extrusion cooking. Recent advances. Adv Exp Med Biol 434, 109-121.

30. Singh S, Gamlath S \& Wakeling L (2007) Nutritional aspects of food extrusion: a review. Int J Food Sci Technol 42, 916-929.

31. Brennan MA, Menard C, Roudaut G, et al. (2012) Amaranth, millet and buckwheat flours affect the physical properties of extruded breakfast cereals and modulates their potential glycaemic impact. Starch 64, 392-398.

32. Brennan MA, Monro JA \& Brennan CS (2008) Effect of inclusion of soluble and insoluble fibres into extruded breakfast cereal products made with reverse screw configuration. Int J Food Sci Technol 43, 2278-2288.

33. European Food Safety Authority (EFSA) Panel on Dietetic Products, Nutrition, and Allergies (NDA) (2010) Scientific
Opinion on Dietary Reference Values for carbohydrates and dietary fibre. EFSA J 8, 1462.

34. Rippe JM \& Angelopoulos TJ (2016) Relationship between added sugars consumption and chronic disease risk factors: current understanding. Nutrients 8, 697.

35. Buttriss J (1999) Nutrition and Food Processing: Briefing Paper. London: British Nutrition Foundation.

36. Ktenioudaki A, Alvarez-Jubete L \& Gallagher E (2015) A review of the process-induced changes in the phytochemical content of cereal grains: the breadmaking process. Crit Rev Food Sci Nutr 55, 611-619.

37. O'Connor A (2012) An overview of the role of bread in the UK diet. Nutr Bull 37, 193-212.

38. Gobbetti M, De Angelis M, Di Cagno R, et al. (2019) Novel insights on the functional/nutritional features of the sourdough fermentation. Int J Food Microbiol 302, 103-113.

39. Vrcek IV, Cepo DV, Rasic D, et al. (2014) A comparison of the nutritional value and food safety of organically and conventionally produced wheat flours. Food Chem 143, 522-529.

40. Federation of Bakers Ltd (2019) How bread is made: production methods. https://www.fob.uk.com/about-the-breadindustry/how-bread-is-made/production-methods/ (accessed September 2020).

41. Papageorgiou M \& Skendi A (2018) Introduction to cereal processing and by-products. In Sustainable Recovery and Reutilization of Cereal Processing By-Products, pp. 1-25 [CM Galanakis, editor]. Cambridge: Woodhead Publishing.

42. Kent NL \& Evans AD (1994) Technology of Cereals: An Introduction for Students of Food Science and Agriculture, 4th ed. Cambridge: Woodhead Publishing.

43. Fardet A (2010) New hypotheses for the health-protective mechanisms of whole-grain cereals: what is beyond fibre? Nutr Res Rev 23, 65-134.

44. Oghbaei M \& Prakash J (2013) Effect of fractional milling of wheat on nutritional quality of milled fractions. Trends Carbohyd Res 5, 52-58.

45. Asp NG (1992) Resistant Starch. Proceedings for the 2nd plenary meeting of EURESTA: European FLAIR Concerted Action No. 11 on physiological implications of the consumption of resistant starch in man. Crete, 29 May-2 June 1991. Eur J Clin Nutr 46, Suppl. 2, S1-S148.

46. Birt DF, Boylston T, Hendrich S, et al. (2013) Resistant starch: promise for improving human health. Adv Nutr $\mathbf{4}, 587-601$.

47. Lockyer S \& Nugent AP (2017) Health effects of resistant starch. Nutr Bull 42, 10-41.

48. Slavin JL, Jacobs D \& Marquart L (2001) Grain processing and nutrition. Crit Rev Biotechnol 21, 49-66.

49. Luithui Y, Baghya Nisha R \& Meera MS (2019) Cereal byproducts as an important functional ingredient: effect of processing. J Food Sci Technol 56, 1-11.

50. García-Estepa RM, Guerra-Hernández E \& García-Villanova B (1999) Phytic acid content in milled cereal products and breads. Food Res Int 32, 217-221.

51. Ramberg J \& McAnalley B (2002) From farm to the kitchen table: a review of nutrient losses in foods. Glycosci Nutr 3, 1-12.

52. Oghbaei M \& Prakash J (2016) Effect of primary processing of cereals and legumes on its nutritional quality: a comprehensive review. Cogent Food Agric 2, 1136015.

53. Coulibaly A, Kouakou B \& Chen J (2011) Phytic acid in cereal grains: structure, healthy or harmful ways to reduce phytic acid in cereal grains and their effects on nutritional quality. Am J Plant Nutr Fertil Technol 1, 1-22.

54. Graf E, Empson KL \& Eaton JW (1987) Phytic acid. A natural antioxidant. J Biol Chem 262, 11647-11650.

55. Aune D, Chan DS, Lau R, et al. (2011) Dietary fibre, whole grains, and risk of colorectal cancer: systematic review and 
dose-response meta-analysis of prospective studies. BMJ 343, d6617.

56. Suma RC, Sheetal G, Jyothi LA, et al. (2007) Influence of phytin phosphorous and dietary fibre on in vitro iron and calcium bioavailability from rice flakes. Int J Food Sci Nutr 58, 637-643.

57. Sandhu K, Punia S \& Kaur M (2017) Fermentation of cereals: a tool to enhance bioactive compounds. In Plant Biotechnology :Recent Advancements and Developments, pp. 157-170 [SK Gahlawat, RK Salar, P Siwach, JS Duhan, S Kumar and P Kaur, editors]. Singapore: Springer Nature Singapore.

58. Majzoobi M, Pashangeh S, Farahnaky A, et al. (2014) Effect of particle size reduction, hydrothermal and fermentation treatments on phytic acid content and some physicochemical properties of wheat bran. I Food Sci Technol 51, 2755-2761.

59. Gupta RK, Gangoliya SS \& Singh NK (2015) Reduction of phytic acid and enhancement of bioavailable micronutrients in food grains. J Food Sci Technol 52, 676-684.

60. McKevith B (2004) Nutritional aspects of cereals. Nutr Bull 29, 111-142.

61. Thomson BM (2009) Stability of added iodine in processed cereal foods. Food Addit Contam Part A Chem Anal Control Expo Risk Assess 26, 25-31.

62. Nayak B, Liu RH \& Tang J (2015) Effect of processing on phenolic antioxidants of fruits, vegetables, and grains - a review. Crit Rev Food Sci Nutr 55, 887-919.

63. Carnovale E \& Lintas C (1995) Dietary fibre: effect of processing and nutrient interactions. Eur J Clin Nutr 49, Suppl. 3, S307-S311.

64. Björck I, Nyman M \& Asp NG (1984) Extusion cooking and dietary fiber: effects on dietary fiber content and on degradation in the rat intestinal tract. Cereal Chem 61, 174-179.

65. Vaidya RH \& Sheth MK (2011) Processing and storage of Indian cereal and cereal products alters its resistant starch content. J Food Sci Technol 48, 622-627.

66. Ma Z \& Boye JI (2018) Research advances on structural characterization of resistant starch and its structure-physiological function relationship: a review. Crit Rev Food Sci Nutr 58, 1059-1083.

67. Federation of Bakers Ltd (1998) Statutory Instrument 1998 No 141: The Bread and Flour Regulations. https://www.fob.uk. com/wp-content/uploads/2016/11/bread-and-flour-regulations. pdf (accessed October 2019).

68. Federation of Bakers Ltd (2008) Legislations. https://www. fob.uk.com/about-the-bread-industry/how-bread-is-made/ legislation/ (accessed October 2019).

69. Crider KS, Bailey LB \& Berry RJ (2011) Folic acid food fortification - its history, effect, concerns, and future directions. Nutrients 3, 370-384.

70. Caldwell EF \& Kadan RS (2004) Breakfast cereals. In Encyclopedia of Grain Science, pp. 201-206 [C Wrigley, H Corke and CE Walker, editors]. Cambridge, MA: Academic Press.

71. Priebe MG \& McMonagle JR (2016) Effects of ready-to-eatcereals on key nutritional and health outcomes: a systematic review. PLOS ONE 11, e0164931.

72. European Food Safety Authority (EFSA) (2016) The 2016 European Union report on pesticide residues in food. EFSA J 16, e05348.

73. Alldrick AJ (2010) Contribution of grain processing to food safety. In Cereal Grains: Assessing and Managing Quality, pp. 342-366 [CW Wrigley and IL Batey, editors]. Cambridge: Woodhead Publishing.

74. Kaushik G (2015) Effect of processing on mycotoxin content in grains. Crit Rev Food Sci Nutr 55, 1672-1683.
75. Cheli F, Pinotti L, Rossi L, et al. (2013) Effect of milling procedures on mycotoxin distribution in wheat fractions. LWT Food Sci Technol 54, 307-314.

76. Thielecke F \& Nugent AP (2018) Contaminants in grain - a major risk for whole grain safety? Nutrients 10, 1213.

77. Alldrick AJ (2017) Processing (flour milling). In Cereal Grains: Assessing and Managing Quality, pp. 393-424 [CW Wrigley and IL Batey, editors]. Cambridge: Woodhead Publishing.

78. Krishnakumar T \& Visvanathan R (2014) Acrylamide in food products: a review. J Food Proc Technol 5, 7.

79. European Food Safety Authority (EFSA) (2017) Commission regulation (EU) 2017/2158 of 20 November 2017 establishing mitigation measures and benchmark levels for the reduction of the presence of acrylamide in food. Official Journal of the European Union, L304/24. https://eur-lex.europa.eu/eli/ reg/2017/2158/oj (accessed September 2020).

80. European Commission (2017) Commission Regulation (EU) 2017/2158 of 20 November 2017 establishing mitigation measures and benchmark levels for the reduction of the presence of acrylamide in food. Official Journal of the European Union. https://eur-lex.europa.eu/eli/reg/2017/2158/oj（accessed September 2020).

81. Knutsen HK, Alexander J, Barregård L, et al. (2017) Risks for public health related to the presence of furan and methylfurans in food. EFSA J 15, e05005.

82. Kettlitz B, Scholz G, Theurillat V, et al. (2019) Furan and methylfurans in foods: an update on occurrence, mitigation, and risk assessment. Comp Rev Food Sci Food Safety 18, 738-752.

83. Weaver CM, Dwyer J, Fulgoni VL 3rd, et al. (2014) Processed foods: contributions to nutrition. Am J Clin Nutr 99, 1525-1542.

84. McKevith B \& Jarzebowska A (2010) The role of breakfast cereals in the UK diet: headline results from the National Diet and Nutrition Survey (NDNS) year 1. Nutr Bull 35, 314-319.

85. Toma RC \& Curtis D (1989) Ready-to-eat cereals: role in a balanced diet. Cereal Foods World 34, 378-390.

86. Weegels PL (2019) The future of bread in view of its contribution to nutrient intake as a starchy staple food. Plant Foods Hum Nutr 74, 1-9.

87. Miller HE, Rigelhof F, Marquart L, et al. (2000) Antioxidant content of whole grain breakfast cereals, fruits and vegetables. J Am Coll Nutr 19, 312S-319S.

88. Ryan L, Thondre PS \& Henry CJK (2011) Oat-based breakfast cereals are a rich source of polyphenols and high in antioxidant potential. J Food Comp Anal 24, 929-934.

89. Michels N, De Henauw S, Beghin L, et al. (2016) Ready-to-eat cereals improve nutrient, milk and fruit intake at breakfast in European adolescents. Eur J Nutr 55, 771-779.

90. Laskowski W, Gorska-Warsewicz H, Rejman K, et al. (2019) How important are cereals and cereal products in the average Polish diet? Nutrients 11, 679 .

91. Williams PG (2014) The benefits of breakfast cereal consumption: a systematic review of the evidence base. Adv Nutr $\mathbf{5}$, 636S-673S.

92. Williamson CS (2010) Breakfast cereals - why all the bad press? Nutr Bull 35, 30-33.

93. Devlin NF, McNulty BA, Gibney MJ, et al. (2013) Whole grain intakes in the diets of Irish children and teenagers. Br J Nutr 110, 354-362.

94. Bellisle F, Hébel P, Salmon-Legagneur A, et al. (2018) Breakfast consumption in French children, adolescents, and adults: a nationally representative cross-sectional survey examined in the context of the International Breakfast Research Initiative. Nutrients 10, 1056. 
95. Vatanparast H, Islam N, Patil RP, et al. (2019) Consumption of ready-to-eat cereal in Canada and its contribution to nutrient intake and nutrient density among Canadians. Nutrients 11, 1009.

96. eufic (The European Food Information Council) (2014) Bread: a nutritious staple. https://www.eufic.org/en/healthy-living/ article/bread-a-nutritious-staple (accessed December 2019).

97. Lockyer S \& Spiro A (2020) The role of bread in the UK diet: an update. Nutr Bull 45, 133-164.

98. Public Health England (2011) SACN iron and health report: The Scientific Advisory Committee on Nutrition recommendations on iron and health, and consumption of red and processed meat. https://www.gov.uk/government/publications/ sacn-iron-and-health-report (accessed October 2019).

99. Julia C, Martinez L, Alles B, et al. (2018) Contribution of ultraprocessed foods in the diet of adults from the French NutriNetSanté study. Public Health Nutr 21, 27-37.

100. Shewry PR \& Hey SJ (2016) Do we need to worry about eating wheat? Nutr Bull 41, 6-13.

101. Shewry PR (2018) Do ancient types of wheat have health benefits compared with modern bread wheat? J Cereal Sci $\mathbf{7 9}$, 469-476.

102. Jacobs DR Jr, Meyer HE \& Solvoll K (2001) Reduced mortality among whole grain bread eaters in men and women in the Norwegian County Study. Eur J Clin Nutr 55, 137-143.

103. European Food Safety Authority (EFSA) (2011) Scientific Opinion on the substantiation of health claims related to beta-glucans from oats and barley and maintenance of normal blood LDL-cholesterol concentrations, increase in satiety leading to a reduction in energy intake, reduction of post-prandial glycaemic responses and 'digestive function' pursuant to Article 13(1) of Regulation (EC) No 1924/2006. EFSA J9, 2207.

104. European Food Safety Authority (EFSA) Panel on Dietetic Products, Nutrition and Allergies (NDA) (2010) Scientific Opinion on the substantiation of health claims related to wheat bran fibre and increase in faecal bulk (ID 3066), reduction in intestinal transit time (ID 828, 839, 3067, 4699) and contribution to the maintenance or achievement of a normal body weight (ID 829) pursuant to Article 13(1) of Regulation (EC) No 1924/2006. EFSA J 8, 1817.

105. Seal CJ, Nugent AP, Tee ES, et al. (2016) Whole-grain dietary recommendations: the need for a unified global approach. Br J Nutr 115, 2031-2038.

106. Becker W, Møller A, Ireland J, et al. (2008) Proposal for structure and detail of a EuroFIR Standard on food composition data. II: Technical Annex. http://archives.foodcomp.info/ eurofir/Downloads/TechnicalAnnex/EuroFIR_Tech_Annex_ 2008_final.pdf (accessed July 2020).

107. Ireland JD \& Møller A (2010) LanguaL food description: a learning process. Eur J Clin Nutr 64, Suppl. 3, S44-S48.

108. European Food Safety Authority (EFSA) (2015) The food classification and description system FoodEx 2 (revision 2). EFSA Supporting Publications 12, 804E.

109. Slimani N, Deharveng G, Southgate DA, et al. (2009) Contribution of highly industrially processed foods to the nutrient intakes and patterns of middle-aged populations in the European Prospective Investigation into Cancer and Nutrition study. Eur J Clin Nutr 63, Suppl. 4, S206-S225.

110. Lecerf J-M (2018) Ultra-processed foods: a discussed new concept. Med Mal Metab 12, 381-386.
111. Programme national nutrition santé (PNNS) (2018) Programme national nutrition santé 2019-2023 (National health nutrition programme 2019-2023). https://solidaritessante.gouv.fr/IMG/pdf/pnns4_2019-2023.pdf (accessed March 2020).

112. Leme ACB, Fisberg RM, Thompson D, et al. (2019) Brazilian children's dietary intake in relation to Brazil's New Nutrition Guidelines: a systematic review. Curr Nutr Rep 8, 145-166.

113. Webb D \& Byrd-Bredbenner C (2015) Overcoming consumer inertia to dietary guidance. Adv Nutr 6, 391-396.

114. Food and Agriculture Organization of the United Nations (2010) Sustainable diets and biodiversity: directions and solutions for policy, research and action. http://www.fao.org/3/ i3004e/i3004e.pdf (accessed June 2020).

115. National Food Agency (2015) Swedish dietary guidelines. https:// www.livsmedelsverket.se/globalassets/publikationsdatabas/ rapporter/2015/rapp-hanteringsrapport-engelska-omslaginlaga-bilagor-eng-version.pdf?AspxAutoDetectCookieSupport=1 (accessed July 2020).

116. Ministry of Health of Brazil (2014) Dietary guidelines for the Brazilian population. https://www.paho.org/hq/dmdocuments/ 2015/dietary-guides-brazil-eng.pdf (accessed July 2020).

117. Health Council of the Netherlands (2015) Dutch dietary guidelines 2015. https://www.healthcouncil.nl/documents/advisoryreports/2015/11/04/dutch-dietary-guidelines-2015 (accessed July 2020).

118. Steenson S \& Buttriss JL (2020) The challenges of defining a healthy and 'sustainable' diet. Nutr Bull 45, 206-222.

119. Food and Agriculture Organization of the United Nations (2017) The future of food and agriculture: trends and challenges. http://www.fao.org/3/a-i6583e.pdf (accessed October 2019).

120. Public Health England (2018) National Diet and Nutrition Survey: Results from Years 7 and 8 (Combined) of the Rolling Programme (2014/2015 to 2015/2016). London: Public Health England.

121. Kramer GFH, Martinez EV, Espinoza-Orias ND, et al. (2018) Comparing the performance of bread and breakfast cereals, dairy, and meat in nutritionally balanced and sustainable diets. Front Nutr 5, 51.

122. Jeswani HK, Hellweg S \& Azapagic A (2018) Accounting for land use, biodiversity and ecosystem services in life cycle assessment: impacts of breakfast cereals. Sci Total Environ 645, 51-59.

123. Dolci G, Nessi S, Rigamonti L, et al. (2016) Life cycle assessment of waste prevention in the delivery of pasta, breakfast cereals, and rice. Integr Environ Assess Manag 12, 445-458.

124. Chaudhary A, Marinangeli CPF, Tremorin D, et al. (2018) Nutritional combined greenhouse gas life cycle analysis for incorporating Canadian yellow pea into cereal-based food products. Nutrients 10, 490.

125. Willett W, Rockstrom J, Loken B, et al. (2019) Food in the Anthropocene: the EAT-Lancet Commission on healthy diets from sustainable food systems. Lancet 393, 447-492.

126. BAKERpedia (2020) Bread Processing. Also known as bread manufacture process. https://bakerpedia.com/processes/ bread-processing/ (accessed January 2020).

127. United States Department of Agriculture, Agricultural Research Service (2020) Nutrient database. https://fdc.nal. usda.gov/index.html (accessed December 2019). 